\title{
SISTEM BUKA TUTUP PINTU OTOMATIS BERBASIS SUARA MANUSIA
}

\author{
Sinta Ariyanti ${ }^{1}$, Slamet Seno Adi ${ }^{2}$ \& Sugeng Purbawanto ${ }^{3}$ \\ ${ }^{1,2,3}$ Universitas Negeri Semarang \\ E-mail: ariyanti.sinta@student.unnes.ac.id
}

\begin{abstract}
Biometric identification is one of the media on the operation of the system of home automation are much sought after. This is because conventional identification such as the use of your PIN, password, and a key card is already not enough reliable, in terms of security and how to operate. Biometrics is essentially an introduction to someone based on the unique personality of each person owned such as facial recognition, fingerprints, voice recognition, the introduction of the retina, and signature. Voice recognition is a process to identify a person by recognizing speech from that person. The purpose of this research is to know the success rate of the giving of the commandments on the system open close the door automatically using voice recognition. The methods used in this study is the method waterfall and consist of systems analysis, the design, implementation, and testing. This system uses the module Easy VR as an introduction to his voice. Easy device VR 3.0 can be an alternative in the build system-based voice recognition, as have a number of benefits that is its small size, has a user-defined feature speaker dependent, so for its implementation can be minimize the complexity of installation and configuration of the function of the device is relatively simple. This study uses two words used to code the words "buka" and "tutup". The success of the grant of the injunction on testing tools by the person authorized is 95\% for the word "buka", and 90\% for the word "tutup".
\end{abstract}

Keywords: biometrik, waterfall, Easy VR

ABSTRAK

Identifikasi biometrik adalah salah satu media pada pengoperasian sistem otomasi rumah yang banyak dicari. Hal tersebut dikarenakan pada identifikasi konvensional seperti penggunaan PIN, kata sandi, dan kartu kunci belum cukup andal, dalam hal keamanan dan cara pengoperasian. Biometrik pada dasarnya adalah pengenalan seseorang berdasarkan karakteristik pribadi unik dari setiap orang yang dimiliki seperti pengenalan wajah, sidik jari, pengenalan suara, pengenalan retina, dan tanda tangan. Pengenalan suara adalah proses untuk mengidentifikasi seseorang melalui pengenalan suara orang tersebut. Tujuan penelitian ini adalah untuk mengetahui tingkat keberhasilan pemberian perintah pada sistem buka tutup pintu secara otomatis dengan menggunakan pengenalan suara. Metode yang digunakan dalam penelitian ini adalah metode waterfall yang terdiri atas analisis sistem, perancangan, implementasi, dan pengujian. Sistem ini menggunakan modul Easy VR untuk pengenalan suara. VR 3.0 sebagai perangkat yang mudah menjadi alternatif dalam membangun sistem pengenalan berbasis suara, karena memiliki sejumlah manfaat yaitu berkapasitas kecil, memiliki fitur speaker yang menyesuaikan kebutuhan pengguna, sehingga untuk implementasinya dapat meminimalisir kerumitan instalasi dan konfigurasi fungsi perangkat yang relatif sederhana. Penelitian ini menggunakan dua kata yang digunakan untuk mengkodekan, yaitu kata "buka" dan "tutup". Keberhasilan pemberian perintah pada alat pengujian oleh orang yang berwenang adalah $95 \%$ untuk kata "buka", dan 90\% untuk kata "tutup".

Kata kunci: biometrik, waterfall, Easy VR

\section{PENDAHULUAN}

Identifikasi biometrik merupakan salah satu media pada pengoperasian sistem home automation yang banyak diminati ${ }^{(1)}$. Hal ini karena identifikasi konvensional seperti penggunaan PIN, password, kartu dan kunci sudah tidak cukup handal, dari segi keamanan dan cara pengoperasiannya ${ }^{(2)}$. Biometrik pada dasarnya merupakan pengenalan seseorang berdasarkan kepribadian unik yang dimiliki setiap orang seperti pengenalan wajah, sidik 
jari, pengenalan suara, pengenalan retina, dan tanda tangan ${ }^{(3)}$.

Pengenalan suara bekerja dengan manganalisis fitur suara antara individu, setiap orang memiliki pola suara unik yang berasal dari pola anatomi mereka (ukuran serta bentuk mulut dan tenggorokan ) dan pola perilaku (nada suara, gaya, aksen bicara) ${ }^{(4)}{ }^{(5)}$. Pengoperasian sistem ini sangat mudah dan tidak memerlukan energi yang banyak, hal tersebut yang menjadi alasan pengenalan suara sangat cocok digunakan sebagai media pengoperasian home automation ${ }^{(1)}$.

Pintu rumah tersebut dapat dikontrol dengan dua mekanisme pengenalan suara yaitu voice recognition dan speech recognition Voice recognition berbeda dengan speech recognition, voice recognition membantu pengguna untuk mencocokan suara dengan suara pengguna yang telah divalidasi sebelumnya, dan memverifikasi kecocokan suara tersebut sehingga memenuhi syarat identifikasi biometrik ${ }^{(6)}$. Oleh karena itu voice recognition cocok digunakan sebagai pengontrol pintu, karena berkaitan dengan integritas pengguna yang diizinkan untuk mengakses pintu ${ }^{(7)}$.

Penelitian terdahulu yang menggunakan modul Easy $V R$ sebagai pengenalan suara untuk mengontrol peralatan rumah yaitu sebagai kontrol untuk menghidupkan dan mematikan kipas angin dan lampu. Pada penelitian tersebut kata yang digunakan sebagai kode adalah "Action", "Down", "One", dan "Berdasarkan uraian yang telah dijelaskan , pada penelitian ini dengan judul "sistem buka tutup pintu otomatis berbasis suara manusia" menggunakan modul Easy VR sebagai modul pengenalan suaranya dan digunakan kata "buka" untuk kode membuka pintu, serta kata "tutup" untuk menutup pintu. Tujuannya agar pengujian yang dilakukan oleh pengguna yang berwenang dengan suara yang sudah valid presentase tingkat keberhasilannya lebih dari $90 \%$ dengan pengaturan tingkat sensitifitas Easy VR normal level.

Stop" dengan tingkat keberhasilan akurasinya $90 \%$, selain empat kata tersebut juga menggunakan kata "Turn" dengan keberhasilan akurasinya sebesar $63 \%$, dan kata "Up" sebesar 76,67\%. Pengujian tersebut dilakukan dengan mengucapkan masingmasing kata sebanyak 60 kali $^{(8)}$.

\section{METODE}

Penelitian ini dilaksanakan di Laboratorium Elektronika Jurusan Teknik Elektro Universitas Negeri Semarang pada bulan Oktober 2017. Metode yang digunakan dalam penelitian ini adalah metode pengembangan waterfall. Adapun menurut ${ }^{(9)}$ tahapan - tahapan dalam model pengembangan waterfall yaitu analisis sistem (analysis), perancangan (design), implementasi (implementation), pengujian (testing).

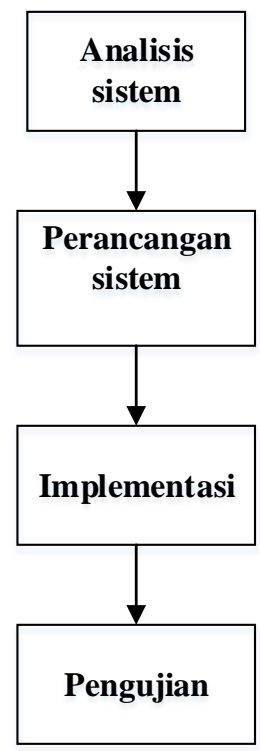

Gambar 1. Tahap Model Waterfall ${ }^{(10)}$

Tahap analisis merupakan tahapan yang dilakukan setelah melakukan pengumpulan data untuk mengidentifikasi dan mengevaluasi permasalahan, kesempatan, hambatan, dan kebutuhan - kebutuhan yang diharapkan sehingga dapat diusulkan perbaikannya. Pada tahap analisis ada beberapa tahapan lagi yang harus dilakukan, yaitu analisis input sistem dan analisis outputnya yang nantinya akan digunakan pada sistem. 
Sistem yang akan dibuat pada penelitian ini adalah prototipe sistem buka tutup pintu otomatis berbasis voice recognition. Sistem ini menggunakan suara sebagai kode untuk membuka atau menutup pintu rumah pengguna. Sistem ini hanya akan mengenali suara pemilik rumah yang sebelumnya sudah dilakukan pengambilan sampel suara dan sampel tersebut tersimpan pada database program. Ketika pengguna sistem mengucapkan suara yang sama dengan suara sampling maka pintu rumah dapat membuka. Kata yang digunakan sebagai sampel yaitu kata "buka" untuk membuka pintu dan kata "tutup" untuk menutup pintu.

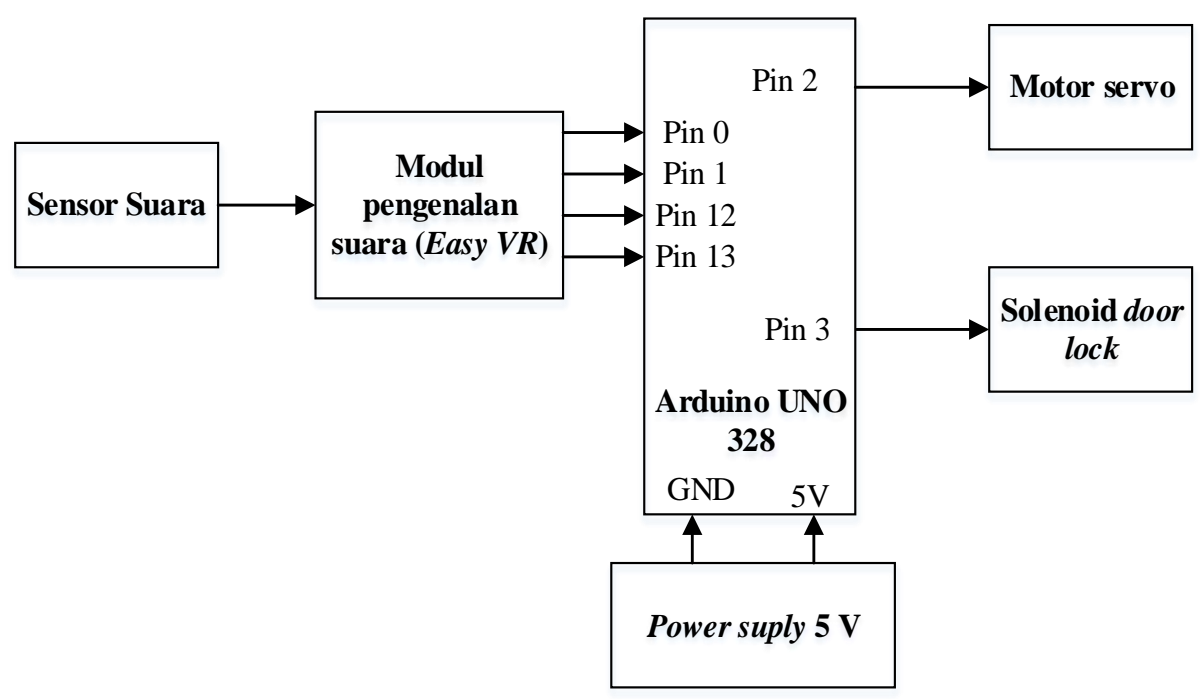

Gambar 2. Diagram blok system

Sistem alat pada penelitian ini terdapat 3 blok utama pembentuk sistem, yaitu blok input atau masukan, output atau keluaran dan proses atau program. Blok input merupakan sensor yang digunakan untuk mendekteksi masukan pada sistem. Suara adalah sebagai masukan sistem dengan menggunakan sensor suara yaitu mikrofon sebagai pendeteksi suara. Data output dari sensor suara akan diteruskan ke Easy $V R$ sebagai pengenalan suara.

Pada blok proses, komponen utama yang digunakan pada sistem adalah mikrokontroler Atmega328 yang terdapat pada platform Arduino Uno. mikrokontroler Atmega328 berperan sebagai pemroses data yang berasal dari keluaran blok input. Keluaran dari sensor suara yang berupa sinyal analog akan diolah atau diproses terlebih dahulu oleh modul pengenalan suara yaitu Easy VR. Pada modul Easy $V R$ terdapat database suara yang telah dijadikan sampel. Easy $V R$ bertugas mencocokkan data keluaran sensor suara yang menjadi data masukan pada Easy $V R$ dengan database suara yang tersimpan pada Easy $V R$ selanjutnya Easy $V R$ akan mengirimkan data ke Arduino, antara Arduino dan modul Easy $V R$ menggunakan komunikasi serial.

Blok output pada sistem ini adalah dua komponen sebagai aktuator yaitu motor servo dan solenoid door lock. Solenoid ini berfungsi sebagai pengunci pintu dan motor servo sebagai penggerak pintu sehingga pintu dapat membuka secara otomatis yang dikontrol oleh mikrokontroler 328 pada platform Arduino.

Perancangan ini dilakukan berdasarkan hasil analisis dari sistem yang akan dibuat. Tujuan dari perancangan ini adalah untuk melihat gambaran awal dari sistem, rangkaian alat, alat dan bahan, dan prinsip kerja alat. Pada tahap desain alat, dimulai dengan membuat rangkian alat pada aplikasi proteus, dimana rangkaian tersebut dijadikan paduan dalam pembuatan alat. Gambar 3 menunjukan skema rangkaian alat yang dibuat. 


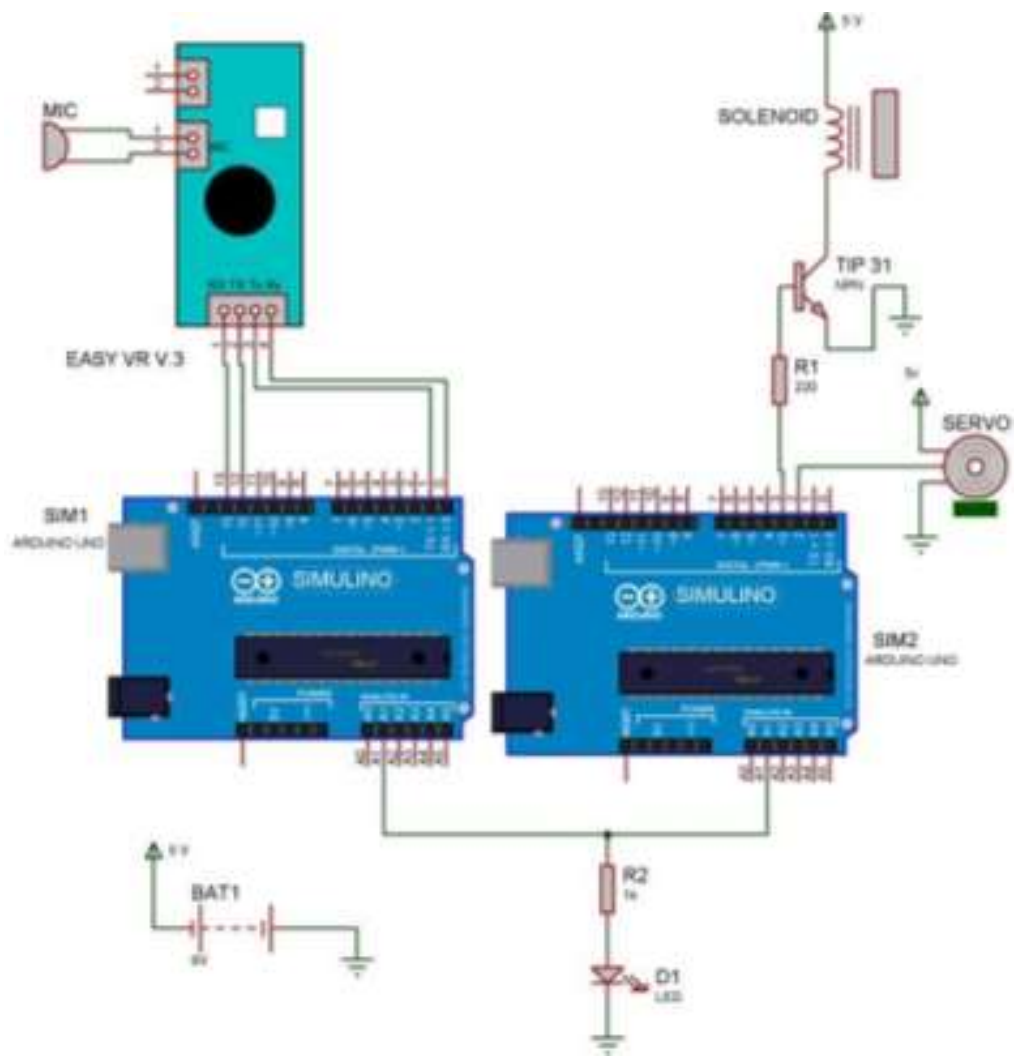

Gambar 3. Skema rangkaian alat

Penelitian ini menggunakan dua perangkat yaitu perangkat keras (hardware) dan perangkat lunak (software). Adapun perangkat keras (hardware) yang digunakan pada penelitian ini sebagai adalah Arduino Uno, Easy VR, Mikrofon, Motor servo, Solenoid door lock, Kayu dan triplek. Perangkat lunak yang digunakan dalam penelitian ini adalah Arduino IDE, Easy VR comander, ISIS Proteus 7, Microsoft Visio 2013, Windows ultimate.

Prinsip kerja alat ini adalah ketika pengguna mengucapkan suara kata buka maka akan membukakan kunci dan menggerakkan motor servo dengan arah pintu terbuka. Kemudian dengan mengucapkan kata tutup maka servo akan bergerak dengan arah pintu tertutup dan kemudian kunci ditutup. Pembuatan suatu alat akan lebih tertata jika sebelumnya dibuat sebuah Flowchart atau diagram alir. Tujuannya adalah agar dalam pembuatan alat pada penelitian ini lebih teratur dan sistematis. Gambar 4 merupakan Flowchart dari sistem yang akan dibuat.

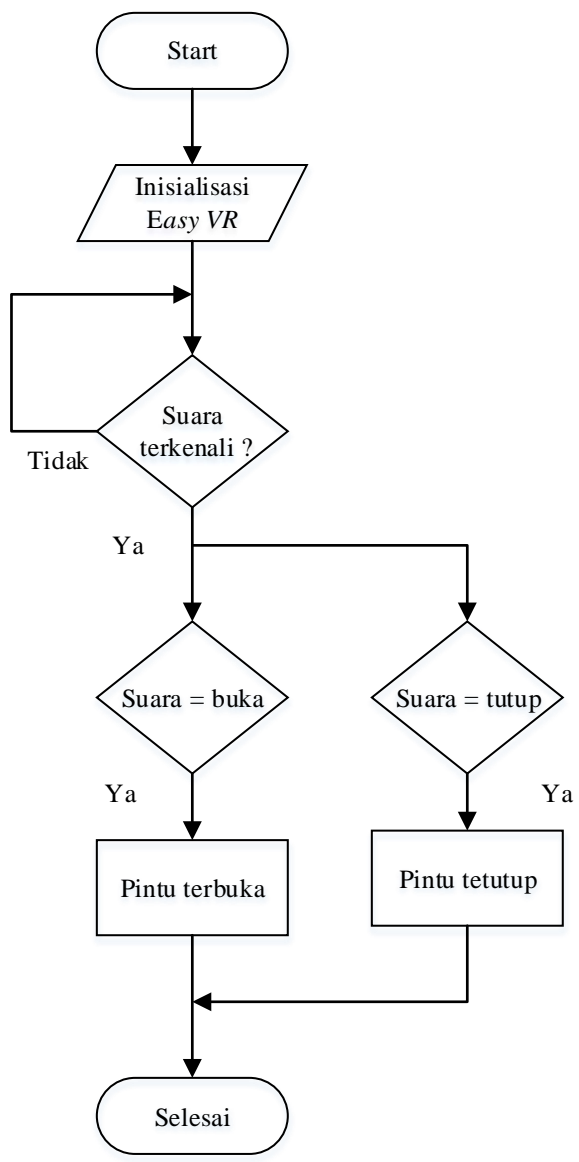

Gambar 4. Flowchart sistem alat 
Hasil dari perancangan sistem diimplementasikan menjadi sebuah prototipe sistem buka tutup pintu otomatis. Pada tahap ini juga dilakukan pengambilan sampel suara. Pengambilan sampel suara dilakukan memalui PC dengan software bawaan dari modul Easy $V R$ yaitu Easy VR commander. Sampel suara yang digunakan adalah kata "buka" dan kata "tutup".

Pengambilan sampel suara dilakukan sebanyak dua kali dengan kondisi ideal atau tidak adanya noise. Kata dan intonasi suara pada setiap pengucapan harus relatif sama agar menghasilkan sampel suara dengan tidak ada kesalahan. Jika pengucapan suara pada pengambilan variasi yang kedua tidak sama dengan pengambilan variasi pengucapan suara yang pertama artinya pengambilan suara tersebut gagal, ditunjukkan seperti gambar 3.6. Oleh karena itu agar Easy VR bekerja dengan baik maka pengambilan variasi suara harus relatif sama dengan sampel pertama.

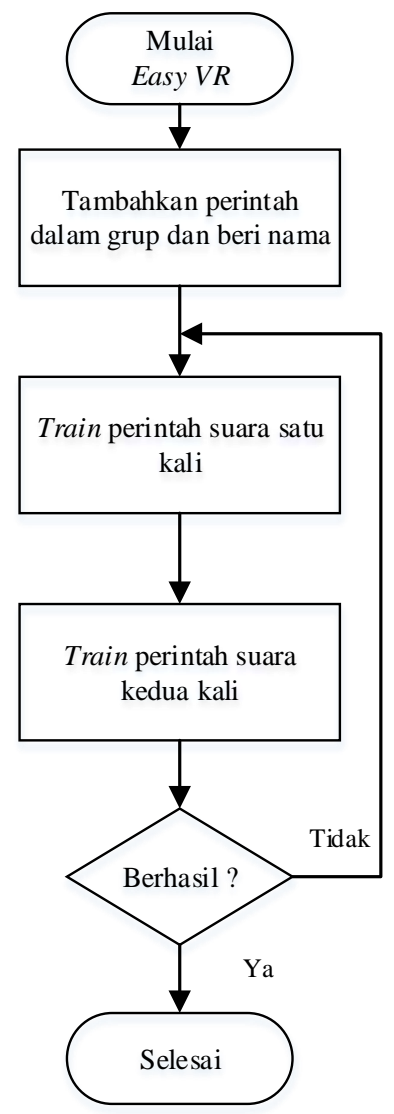

Gambar 5. Flowchart pengambilan sampel suara
Setelah pengambilan suara selanjutnya menyusun program pada Arduino Uno dengan menggunakan data yang berasal dari Easy $V R$ dan pengontrolan motor servo serta solenoid door. Program yang digunakan adalah pemrograman IDE pada Arduino, dimana didalam platform Arduino terdapat mikrokontroler yang berperan sebagai pusat kendali seluruh sistem.

Pada tahap pengujian dilakukan dua pengujian yang pertama pengujian sampling suara pada Easy $V R$ dan pengujian keseluruhan sistem pada prototipe. Pengujian sampling suara dilakukan untuk mengetahui apakah sampel suara yang telah direkam berhasil dideteksi. Sedangkan pengujian keseluruhan sistem dilakukan dengan pemberian perintah langsung kepada alat yang bertujuan untuk mengetahui apakah perintah yang diucapkan dapat membuka pintu atau menutup pintu. Pada pengujian keseluruhan sistem dilakukan dengan pengujian tingkat keberhasilan pemberian perintah suara oleh orang yang suaranya sudah dijadikan sampel, pengujian tingkat keberhasilan pemberian perintah oleh orang lain yang suaranya belum dijadikan sampel, pengukuran amplitudo suara dari pengucapan pemberian perintah oleh orang yang suaranya dijadikan sampel.

Tujuan dari pengujian sampling suara pada program adalah untuk menguji apakah hasil pengambilan sampel suara yang telah dituliskan pada program Easy $V R$ dapat diterapkan pada sistem. Pengujian ini dilakukan dengan menghubungkan Easy $V R$ ke PC atau laptop dengan konektor USB.

Pengujian keseluruhan system alat dilakukan dengan beberapa pengujian. Pengujian pemberian perintah oleh orang yang suaranya dijadikan sampel dan orang lain bertujuan untuk mengetahui tingkat keberhasilan alat dalam mendeteksi pemberian perintah oleh orang yang suaranya telah dijadikan sampel (penulis sendiri). Pengujian ini dilakukan dengan pemberian perintah suara oleh orang yang suaranya telah dijadikan sampel dan tersimpan pada database program. 
Kata yang digunakan sebagai sampel adalah kata "buka" dan kata "tutup". Pada pengujian ini dilakukan dengan mengucapkan kata sampel sebanyak sepuluh kali. Kemudian akan dihitung seberapa banyak jumlah pengucapan suara yang berhasil.

Pengujian pemberian perintah oleh orang lain yang suaranya belum dijadikan sampel ini dilakukan oleh lima orang yang berebeda, kelima orang tersebut suaranya belum dijadikan sampel dan belum tersimpan pada database. Kata yang diucapkan sama seperti pengujian yang sebelumnya yaitu kata "buka" dan kata "tutup". Masing - masing orang melakukan pemberian perintah sebanyak sepuluh kali, kemudian dihitung berapa kali pengucapan kata yang dapat berhasil direspon oleh sistem yaitu dapat menggerakkan motor servo dengan arah buka atau tutup sesuai dengan kata yang diucapkan. Hasil dari pengujian ini adalah presentase tingkat keberhasilan pengucapan kata "buka" dan "tutup".

Pengukuran amplitudo suara dari pengucapan pemberian perintah oleh orang yang suaranya dijadikan sampel bertujuan untuk mengetahui berapa besar amplitudo suara yang dapat direspon oleh alat. Pengujian awal yang dilakukan adalah mengukur amplitudo suara yang diucapkan saat pengambilan sampling pemberian perintah pada Easy VR Commander. Selanjutnya mengukur amplitudo suara yang diucapkan saat pengujian pemberian perintah pada alat

\section{HASIL DAN PEMBAHASAN}

Hasil dari penelitian ini adalah dapat dirancang sistem buka tutup pintu otomatis berbasis suara manusia. Pada sistem ini, pengenalan suaranya menggunakan modul Easy VR. Pusat kendali dan kontrol digunakan Arduino Uno dengan Atmega 328. Motor servo digunakan untuk menggerakkan pintu secara otomatis. Ketika pengguna mengucapkan kata "buka" pintu pada maket rumah akan membuka dan jika pengguna menggucapkan kata "tutup" pintu akan menutup.

Tujuan pengujian sampling suara adalah untuk mengetahui apakah suara yang terekam dapat digunakan dalam sistem atau tidak. Pada pengujian ini dilakukan pemberian perintah oleh orang yang berwenang dan oleh lima orang lain. Presentase keberhasilan pemberian perintah pada program ditunjukkan pada Tabel 1.

Tabel 1. Presentase keberhasilan pemberian perintah pada program

\begin{tabular}{ccccccc}
\hline \multirow{2}{*}{$\begin{array}{c}\text { Pemberian } \\
\text { perintah }\end{array}$} & \multicolumn{2}{c}{$\begin{array}{c}\text { Jumlah pemberian perintah } \\
\text { suara }\end{array}$} & $\begin{array}{c}\text { Jumlah keberhasilan } \\
\text { pengucapan }\end{array}$ & \multicolumn{2}{c}{$\begin{array}{c}\text { Presentase Tingkat } \\
\text { keberhasilan pengucapan }\end{array}$} \\
\cline { 2 - 6 } & Buka & Tutup & Buka & Tutup & Buka & Tutup \\
\hline Saya & 20 & 20 & 20 & 18 & $100 \%$ & $90 \%$ \\
Orang ke 1 & 20 & 20 & 6 & 5 & $30 \%$ & $25 \%$ \\
Orang ke 2 & 20 & 20 & 7 & 4 & $35 \%$ & $20 \%$ \\
Orang ke 3 & 20 & 20 & 5 & 2 & $25 \%$ & $10 \%$ \\
Orang ke 4 & 20 & 20 & 4 & 2 & $20 \%$ & $10 \%$ \\
Orang ke 5 & 20 & 20 & 2 & 1 & $10 \%$ & $5 \%$ \\
\hline
\end{tabular}

Pengujian ini dilakukan dengan cara melakukan pemberian perintah langsung terhadap alat yang dibuat. Tujuan dari pengujian ini adalah untuk mengetahui keberhasilan pemberian perintah terhadap respon alat. Pengujian Pemberian Perintah Oleh Orang yang Sah (Suara yang telah direkam dalam program) bertujuan untuk mengetahui tingkat keberhasilan alat dalam mendeteksi pemberian perintah oleh orang yang suaranya telah dijadikan sample (penulis sendiri). Pengujian ini dilakukan dengan pemberian perintah suara oleh orang yang suaranya telah dijadikan sample dan tersimpan 
pada database program. Kata yang digunakan sebagai sample adalah kata "buka" dan kata "tutup". Pada pengujian ini dilakukan dengan mengucapkan kata sample sebanyak sepuluh kali. Kemudian akan dihitung seberapa banyak jumlah pengucapan suara yang berhasil, hasil akhir pengujian ini adalah presentase tingkat keberhasilan pengucapan masing - masing kata.

Tabel2. Hasil Pengujian pemberian perintah oleh orang yang suaranya telah dijadikan sample

\begin{tabular}{cccc}
\hline $\begin{array}{l}\text { Jenis } \\
\text { kata }\end{array}$ & $\begin{array}{c}\text { Jumlah } \\
\text { penguca- } \\
\text { pan }\end{array}$ & $\begin{array}{c}\text { Jumlah } \\
\text { keberhasil } \\
\text { an }\end{array}$ & $\begin{array}{c}\text { Presentase } \\
\text { keberhasil- } \\
\text { an }\end{array}$ \\
\hline Buka & 20 & 19 & $95 \%$ \\
Tutup & 20 & 18 & $90 \%$ \\
\hline
\end{tabular}

Pengujian Pemberian Perintah Oleh Orang Lain Yang Suaranya Belum Dijadikan Sample dilakukan oleh lima orang yang berbeda, kelima orang tersebut suaranya belum dijadikan sample dan belum tersimpan pada database. Kata yang diucapkan sama seperti pengujian yang sebelumnya yaitu kata "buka" dan kata "tutup". Masing - masing orang melakukan pemberian perintah sebanyak sepuluh kali, kemudian dihitung berapa kali pengucapan kata yang dapat berhasil direspon oleh sistem yaitu dapat menggerakkan motor servo dengan arah buka atau tutup sesuai dengan kata yang diucapkan. Hasil dari pengujian ini adalah presentase tingkat keberhasilan pengucapan kata "buka" dan "tutup".

Tabel 3. Hasil pengujian pemberian perintah oleh 5 orang yang berbeda

\begin{tabular}{ccccccc}
\hline \multirow{2}{*}{ Orang ke } & \multicolumn{2}{c}{$\begin{array}{c}\text { Jumlah pemberian perintah } \\
\text { suara }\end{array}$} & \multicolumn{2}{c}{$\begin{array}{c}\text { Jumlah keberhasilan } \\
\text { pengucapan }\end{array}$} & \multicolumn{2}{c}{$\begin{array}{c}\text { Presentase Tingkat } \\
\text { keberhasilan } \\
\text { pengucapan }\end{array}$} \\
\cline { 2 - 7 } & Buka & Tutup & Buka & Tutup & Buka & Tutup \\
\hline 1 & 20 & 20 & 4 & 1 & $20 \%$ & $5 \%$ \\
2 & 20 & 20 & 4 & 2 & $20 \%$ & $10 \%$ \\
3 & 20 & 20 & 3 & 0 & $15 \%$ & $0 \%$ \\
4 & 20 & 20 & 2 & 1 & $10 \%$ & $5 \%$ \\
5 & 20 & 20 & 0 & 0 & $0 \%$ & $0 \%$ \\
& \multicolumn{2}{l}{ Rata - rata presentase tingkat keberhasilan } & & $13 \%$ & $4 \%$ \\
\hline
\end{tabular}

Hasil dari penelitian ini adalah sebuah prototipe atau rancang bangun berupa maket rumah. Maket rumah diimplementasikan untuk mengetahui gambaran sistem secara keseluruhan. Penelitian ini menggunakan modul pengenalan suara yaitu modul Easy VR yang sudah dilengkapi dengan sensor suaranya yaitu mikrofon jenis omnidirectional electret condenser microphone dengan tipe Horn EM9745P-382. Komponen lain adalah platform Arduino yang di dalamnya terdapat Atmega 328 sebagai pusat kendali sistem. Selain itu sebagai aktuatornya untuk menggerakkan pintu digunakan motor servo 5 volt, dan sebagai pengunci pintu menggunakan solenoid door lock. LED (Light Emitting Diode) juga ditambahkan sebagai indikator keberhasilan suara yang diucapkan pengguna.
Pada penelitian ini dilakukan dua tahap pengujian, yang pertama pengujian sample suara pada software Easy VR Commander. Pada pengujian ini pengguna melakukan percobaan pengucapan suara dengan kata buka dan tutup yang telah dijadikan sample yang sebelumnya telah tersimpan pada database Easy VR Commander. Percobaan dilakukan dengan mengklik ikon test group pada toolbar kemudian setelah muncul perintah Speak Now pengguna mengucapkan kata "buka", jika terdapat warna hijau maka kata tersebut berhasil dideteksi oleh sistem. Begitu juga untuk kata tutup langkah percobaannya sama seperti kata buka, jika kata "tutup" terdapat warna hijaunya maka berhasil dideteksi. Tanda hijau tersebut menunjukkan suara yang diucapkan sam dengan suara yang telah direkam sebelumnya, dan berhasil dideteksi oleh program. Presentase tingkat keberhasilan 
pemberian perintah oleh orang yang berwenang sebesar $100 \%$ untuk kata buka dan $90 \%$ untuk kata tutup. sedang kan rata - rata presentase tingkat keberhasilan pemberian perintah oleh orang lain $24 \%$ kata buka dan $14 \%$ kata tutup.

Pengujian kedua adalah pengujian pada seluruh sistem, pada pengujian ini dilakukakan beberapa percobaan yaitu pengujian pemberian perintah oleh orang yang suaranya berwenang (suaranya telah direkam), pengujian pemberian perintah oleh orang yang suaranya belum direkam pada program

Pengujian pemberian perintah oleh orang yeng suaranya telah dijadikan sample (penulis sendiri). Pada pengujian ini dilakukan dengan pengucapan pemberian perintah kata buka dan tutup sebanyak sepuluh kali. Pengujian ini dilakukan pada kondisi ideal dengan noise rendah. Hasil dari pengujian ini suara yang diucapkan dan berhasil membuka pintu sebanyak 19 kali pengucapan, dan untuk membuka pintu sebanyak 18 kali pengucapan. Presentase dari keberhasilan pengucapan kedua kata tersebut adalah 95\% dan 90\%. Keberhasilan pemberian perintah pada alat yang dibuat masih terdapat kegagalan, dikarenakan pengucapan kata yang kurang jelas serta intonasi yang beda dengan suara yang sebelumnya telah direkam dalam program.

Pengujian pemberian perintah oleh orang yang suaranya belum dijadikan sample. Pada pengujian ini sama seperti pengujian pemberian perintah yang pertama namun dilakukan oleh orang yang berbeda. Pengujian ini dilakukan oleh lima orang yang bebrbeda. Pada pemberian perintah dengan kata buka dari kelima pengucapan tersebut rata - rata presentase tingkat keberhasilan pemberian perintah sebesar $13 \%$ sedang kata tutup sebesar 4\%. Dalam pengujian ini hasil presentase tingkat keberhasilan pemberian perintah cukup rendah dikarenakan suara yang diucapkan oleh orang yang berbeda tidak sama karakteristik dan intonasi suaranya dengan sample suara yang tersimpan, menyebabkan
Easy VR tidak mendeteksi suara yang masuk sehingga suara tidak dapat terkenali.

\section{SIMPULAN}

Hasil dari pengujian pada alat yang dilakukan oleh orang yang berwenang (suara telah terekam pada prigram) besar presentase tingkat keberhasilannya adalah 95\% untuk kata buka dan 90\% untuk kata tutup, sedangkan untuk pemberian perintah oleh orang lain rata - rata presentase keberhasilannya adalah $13 \%$ untuk kata buka dan $4 \%$ untuk kata tutup.

\section{REFERENSI}

[1] Imario, Anjar, Sudiharto, Dodi isaksono and Ariyanto, Endro. The validated voice recognition measurement of several tribes in Indonesia using easy VR 3.0. Case study: The prototype of automated doors. Semarang: IEEE, 2017, 2017 International Seminar on Application for Technology of Information and Communication (iSemantic) ,132-136.

[2] Tumuli, Andika D.L., Najoan, Xaverius N. and Sambul, Alwin M. Implementasi Teknologi Biometrical Identification untuk Login Hotspot. 2017, E-Journal Teknik Informatika, 12(1),1-5. ISSN 2301-8364.

[3] Srivastava, Himanshu. A Comparison Based Study on Biometrics for Human Recognition. 2013, IOSR Journal of Computer Engineering (IOSR-JCE), 15(1), 22-29. e-ISSN: 2278-0661, pISSN: 2278-8727.

[4] Frischholz, Robert W. and Dieckmann, Ulrich. BioID: A Multimodal Biometric Identification System. s.1.: IEEE, 2000. 64-68.

[5] King, Rawlson O'Neil. Speech and Voice Recognition. Biometrics Research Group. [Online] 2014. www.biometricupdate.com/wpcontent/uploads/2014/05/VoiceBiometrics.pdf.

[6] Saini, Preeti and Kaur, Parneet. Automatic Speech Recognition: A Review. 2013, International Journal of Engineering Trends and Technology, 4(2) 
[7] Maiwald, Eric and Sieglein, William. Security Planning and Disaster Recovery 1st Edition. California: McGraw-Hill, 2002.

[8] Hasan, Nurul Fadzilah, Rejab, Mohd R.M. and Sapar, Nurul Hidayah.Implementation of speech recognition home control system using arduino. 2015, ARPN Journal of Engineering and Applied Sciences, 10(23), 17492-17498. ISSN 1819-6608.

[9] Septriyaningrum, Indah Ayu, Nugrahadi, Dodon T. and Ridwan, Ichsan. Perancangan dan pengembangan prototype sistem parkir. 2016, Kumpulan Jurnal Ilmu Komputer (KLIK), 3 (2), 146-155. ISSN: 2406-7857.

[10] Pressman, Roger S. Software Engineering: A Practitioner's Approach, Fifth Ed. Newyork: McGraw-Hill Book Company, 2001. 